\title{
Standing on the brink
}

\author{
MARK C. SERREZE AND JULIENNE C. STROEVE
}

\section{Despite some recovery of the Arctic summer sea ice this year, the signs suggest the transition to a seasonally ice-free Arctic Ocean is underway.}

ch year since 2002 has seen pronounced seasonal minima in Arctic sea ice extent, serving as exclamation points on a more general downward trend. According to analyses by the US National Snow and Ice Data Center, the seasonal minimum for 2008, occurring on 14 September, entered the books as the second-lowest of the satellite era, probably the second-lowest of at least a century, and just behind the standing record set in 2007 (Fig. 1) $)^{1}$. Could a rapid transition to a seasonally ice-free Arctic Ocean be underway? We'll never know except in hindsight, but evidence is growing that if not, we're at its doorstep.

The implications are many. As the summer sea ice cover disappears, the Arctic will become more accessible. Summer 2008 was the second year in a row that the Northwest Passage through the straits of the Canadian Arctic Archipelago was navigable, at least to ice-strengthened ships. The Canadians maintain that they own the passage. The United States doesn't agree. The Northern Sea Route, along the shores of Eurasia, also opened briefly. Milder ice conditions will make it easier to drill for oil and gas in the Beaufort and Chukchi Seas, where new leases are being sold. The US Coast Guard set up temporary bases this summer at Barrow and Prudhoe Bay, Alaska, from which they tested their readiness for a busier Arctic. Potential environmental impacts abound. Polar bears have an uncertain future, as do other ice-dependent species. Coastal erosion is a growing problem for many Arctic communities. Evidence is emerging that loss of the sea ice cover may have impacts on atmospheric circulation and precipitation patterns extending into middle latitudes ${ }^{2,3}$.

\section{YOUNGER AND THINNER}

Sea ice extent is typically defined as the ocean area covered with an ice concentration of at least 15 per cent ${ }^{1}$. Arctic sea ice extent naturally waxes and wanes with the seasons. A quarter-century ago, the seasonal range was usually from about 16 million square kilometres in March to 7 million square kilometres at the end of the summer melt season in September. Over the modern satellite era, which began in late 1978, Arctic ice extent has shown a downward linear trend in all months, with the largest decrease occurring in September ${ }^{4}$. Including 2008, the decline in September sea ice extent stands at about 12 per cent per decade. The linear trend is misleading, however, for the September decline seems to have accelerated since 2002. The extreme seasonal minima of 2007 and 2008 reinforce this tendency. The acceleration is consistent with a growing feedback process linking changes in ice extent and thickness.

Sea ice thickness is best described in terms of a statistical distribution. Consider the situation back in the mid-1980s, when the system was still in a reasonably steady state. In April, about 40 per cent of the distribution of ice would consist of young and fairly thin ice that had formed the previous autumn and winter, the remainder being thicker ice that had survived one or more melt seasons. Generally, the older the ice - the more melt seasons it has survived - the thicker it is. The distribution would change with the seasons. Most of the young, thin ice melted out to form open water areas. Some of the older ice thinned in summer, and a bit melted out. Absorbing solar radiation heated up dark open water areas, with some of this heat melting more ice - a natural feedback process. Ice surviving the summer thickened again the next autumn and winter. Over the course of each year, growth exceeded melt. This difference is roughly balanced by the net export of ice out of the Arctic and into the North Atlantic via Fram Strait. 
In recent years, by comparison, the thickness distribution has shifted. Less of the spring ice cover is old and thick; more of it is young and thin ${ }^{5}$. Ice volume (and mass) has hence declined. Because the ice is thinner at the start of the melt season, open water areas develop earlier than before and become more extensive through summer. The feedback that boosts the seasonal melt process is therefore stronger. The past few years have seen the distribution shift to even thinner spring ice, resulting in even larger open water areas absorbing solar radiation, and an even stronger feedback.

Under a 'business as usual' emissions scenario for the twenty-first century, simulations from the current generation of coupled global climate models - which contributed to the Intergovernmental Panel on Climate Change (IPCC) Fourth Assessment Report - indicate that the Arctic Ocean will become seasonally ice-free, or nearly so, anywhere from 2040 to beyond the year 2100 . All of the simulations show declining September sea ice over the period for which there are observations, but with large model-to-model scatter ${ }^{4,6}$. Nevertheless, consensus on the direction of the simulated change is strong evidence for a role of greenhouse gases in the observed trend. Although large scatter in both model projections and model 'hindcasts' of the past is sobering, a more disturbing finding is that almost all of the hindcast trends in September ice extent are smaller than what has been observed ${ }^{4}$. Furthermore, whereas most simulations show the September ice loss becoming steeper with time in the twenty-first century, as would be expected in response to a growing feedback, this acceleration seems to have already emerged. In other words, compared with the projections from climate models, we are on the fast track of change. One of the only models that can capture the magnitude of the observed trend is Climate Community System Model 3 (CCSM3) from the US National Center for Atmospheric Research.

A further disturbing feature of some simulations of the twenty-first century, most widely studied in CCSM3, is that acceleration of the trend may be especially pronounced, appearing as an abrupt transition to ice-free summer conditions. The transition period may be as short as a decade. Under such a scenario, rising atmospheric greenhouse gas concentrations cause spring ice cover to thin such that it becomes vulnerable to a 'kick' from natural variability that sets the feedback process into high gear. In the CCSM3 simulations, the kicks are associated with an anomalous transport of ocean heat into the Arctic ${ }^{7}$. Other types of kicks - for example, from atmospheric circulation - may appear in simulations from other models.

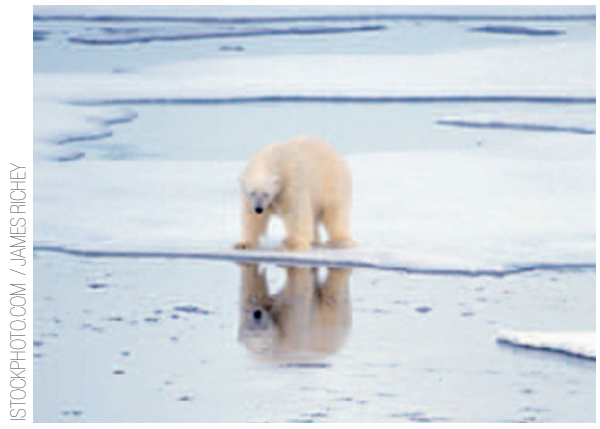

\section{SOURCES OF SPEED}

So why are we on the fast track of change compared with most of the IPCC simulations? Has the ice already thinned to the vulnerable state in which a firm kick could initiate a rapid transition to ice-free summers? Could the observations be telling us that a kick has already occurred? One explanation as to why the hindcast trends are smaller than the observed one is that as a group, the models are too insensitive to the effects of rising greenhouse gas concentrations. Aspects of the system such as ocean coupling, reflection of light from the Earth's surface (albedo), cloud cover and the ice thickness distribution may all be insufficiently represented. It is probably no coincidence that CCSM3, one of the only models that can simulate the observed magnitude of the September trend, has a robust treatment of sea ice processes. An alternative explanation is that natural variability has contributed especially strongly to the rapid disappearance of sea ice. A reasonable conclusion is that both arguments have merit ${ }^{4}$.

\section{The emerging view is that if we're still waiting for the rapid slide towards this ice-free state, we won't be waiting much longer.}

A study published several years ago argued that recent (through 2004) extreme minima in September sea ice extent could be in part understood as a response to the strongly positive phase of the winter Northern Annular Mode, an important mode of large-scale atmospheric variability, from about 1989 to 1995 . When the mode was in its positive phase, shifts in surface wind patterns flushed part of the Arctic's store of thick, old ice into the North Atlantic through Fram Strait, leaving thinner ice prone to melting out in summer ${ }^{8}$. In other words, although the thinning process was dynamically driven by wind rather than driven by heat, it still acted as a trigger. Perhaps when we look back ten years from now, it will be acknowledged as the event that initiated a rapid slide towards a seasonally ice-free Arctic Ocean. Other studies ${ }^{9}$ provide intriguing evidence of oceanic events triggering recent pronounced ice losses.

Perhaps the trigger was pulled more recently. The summer of 2007 was characterized by an unusual pattern of atmospheric circulation, featuring high surface pressure over the Beaufort Sea north of Alaska and low pressure over eastern Siberia. This led to strong and persistent warm winds from the south over the Chukchi and East Siberian Seas, fostering extremely strong melt. After the resulting record-low ice extent in September, unprecedented in satellite observations, over 70 per cent of the sea ice cover in spring 2008 consisted of young, fairly thin ice - an even more extreme situation than in spring 2007.

The eyes of the science community and fascinated citizens worldwide were therefore focused on 2008. Would there be a new record minimum in September of 2008, suggesting the start of a rapid slide, or would there be some recovery? In the end, there was some recovery, albeit only from lowest to second-lowest ice extent. We'll see what happens next year. With sharply rising atmospheric greenhouse gas concentrations, the change to a seasonally ice-free Arctic Ocean seems inevitable. The only question is how fast we get there. The emerging view is that if we're still waiting for the rapid slide towards this ice-free state, we won't be waiting much longer.

Published online: 9 0ctober 2008

doi:10.1038/climate.2008.108

\section{References}

1. Arctic Sea Ice News \& Analysis 24 September 2008; http://nsidc.com/arcticseaicenews/

2. Magnusdottir, G., Deser, C. \& Saravanan, R. J. Climate 17, 857 (2004).

3. Singarayer, J. S., Bamber, J. \& Valdes, P. J. J. Climate 19, 1109 (2006).

4. Stroeve, J., Holland, M. M., Meier, W., Scambos, T. \& Serreze, M. Geophys. Res. Lett. 34, L09501, doi:10.1029/2007GL029703 (2007)

5. Maslanik, J. A., Fowler, C., Stroeve, J., Drobot, S. \& Zwally, J. Geophys. Res. Lett. 34, L24501, doi:10.1029/2007GL032043 (2007).

6. Zhang, X. \& Walsh, J. E. J. Climate 19, 1730 (2006).

7. Holland, M. M., Bitz, C. M. \& Tremblay, B. Geophys. Res. Lett. 33, L23503, doi:10.1029/2006GL028024 (2006).

8. Rigor, I. G. \& Wallace, J. M. Geophys. Res. Lett. 31, L09401, doi:10.1029/2004GL019492 (2004).

9. Shimada, K. et al. Geophys. Res. Lett. 33, L08605, doi:10.1029/2005GL025624 (2006).

Mark C. Serreze and Julienne C. Stroeve are at the National Snow and Ice Data Center, University of Colorado, Boulder. e-mail: serreze@kryos.colorado.edu or stroeve@kryos.colorado.edu 